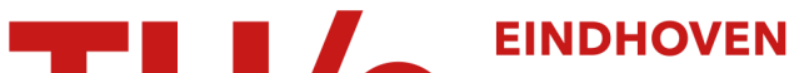 \\ UNIVERSITY OF \\ TECHNOLOGY
}

\section{Stress analysis and fixation problems in joint replacement}

\author{
Citation for published version (APA): \\ Huiskes, H. W. J. (1985). Stress analysis and fixation problems in joint replacement. In N. Berme, A. E. Engin, \& \\ K. M. Correia-da-Silva (Eds.), Biomechanics of Normal and Pathological Human Articulating Joints. Proceedings \\ of the NATO Advanced Study Institute (pp. 337-358). Nijhoff.
}

\section{Document status and date:}

Published: 01/01/1985

\section{Document Version:}

Publisher's PDF, also known as Version of Record (includes final page, issue and volume numbers)

\section{Please check the document version of this publication:}

- A submitted manuscript is the version of the article upon submission and before peer-review. There can be important differences between the submitted version and the official published version of record. People interested in the research are advised to contact the author for the final version of the publication, or visit the $\mathrm{DOI}$ to the publisher's website.

- The final author version and the galley proof are versions of the publication after peer review.

- The final published version features the final layout of the paper including the volume, issue and page numbers.

Link to publication

\section{General rights}

Copyright and moral rights for the publications made accessible in the public portal are retained by the authors and/or other copyright owners and it is a condition of accessing publications that users recognise and abide by the legal requirements associated with these rights.

- Users may download and print one copy of any publication from the public portal for the purpose of private study or research.

- You may not further distribute the material or use it for any profit-making activity or commercial gain

- You may freely distribute the URL identifying the publication in the public portal.

If the publication is distributed under the terms of Article $25 \mathrm{fa}$ of the Dutch Copyright Act, indicated by the "Taverne" license above, please follow below link for the End User Agreement:

www.tue.nl/taverne

Take down policy

If you believe that this document breaches copyright please contact us at:

openaccess@tue.nl

providing details and we will investigate your claim. 
STRESS ANALYSIS AND FIXATION PROBLEMS IN JOINT REPLACEMENT

R. Huiskes

Biomechanics Section, Lab. Exp. Orthopaedics, University of Nijmegen, $6500 \mathrm{HB}$ Nijmegen, The Netherlands

\section{INTRODUCTION}

Artificial joint replacement is a procedure performed relatively often in modern orthopaedic surgery. An estimated total of 65,000 patients annually in the U.S.A. (1), for example, and probably about an equal number in the rest of the world, receive total hip replacement (THR) for relief of pain and restoration of function. Most of these patients are over 60 years of age, and have severe osteoarthritis of the hip. Smaller groups suffer from post-traumatic conditions, rheumatoid arthritis or other disorders. Very few are younger than 50. THR represents major surgery, which is very successful as a treatment of severe disorders of the hip, both from the point of view of immediate post-operative pain relief and restoration of function, as well as its long-term results (1).

Less impressive in numbers, but following as a good second and increasing, is the amount of knee-joint replacements performed on a regular basis. Finger joints, too, are replaced quite frequently, for rheumatoid arthritis patients in particular. Other joints replaced less often are the shoulder, elbow and ankle. Whereas the clinical and engineering design problems in replacements of the various joints differ considerably, the most severe difficulties, those related to fixation of the implants to the bone, have a common denominator. Although this chapter will mainly focus on hip joint replacement, it must be kept in mind that the objectives and methods discussed here are applicable to joint replacement in general.

The success of joint replacement has followed major advances in surgical techniques and biomedical engineering during the last 
20 years. Charnley. (2), in 1960, introduced the use of acrylic cement as a space-filling fixation material and the concept of "low-friction" THR, replacing the acetabular component of the joint with a plastic cup and the femoral component with a metal endoprosthesis (Fig. 1.a). These concepts proved to be viable, and still today form the fundamentals on which many joint replacement procedures rest. Further improvements followed gradually, based on clinical and experimental research. In particular, the metals and plastics used for the prosthetic components became stronger, and the cementing technique matured through the application of cement syringes and pressurization.

Although joint replacement is successful, it is not without problems. Probably, the most severe long-term complication is aseptic loosening. Although the average life-span of the replacement system appears to be adequate in view of the age limitations usually applied to patients, it is certain that its integrity cannot be guaranteed forever. This is indicated by the increasing percentage of protheses that loosen in the course of post-operative time. Aseptic loosening is usually accompanied by failure of the cement mantle and the presence of a soft fibrous tissue layer between the cement mantle and the bone. Sometimes component fracture will occur in addition. Quite often massive bone resorption is seen at the proximal side of the femur after THR. These late complications are a particular threat to patients operated at young ages. However, the fibrous tissue liners at the cement-bone interface are also found to increase progressively in a relatively large number of patients with 5 to 10 years follow-up on postoperative X-rays (e.g. 3). Such liners are usually interpreted as a sign for forthcoming loosening.

The causes and mechanisms of late aseptic loosening are not well understood as yet. Obviously, (fatigue) fracture of prosthetic components is directly related to high stresses, as is fracture of the cement mantle. Massive bone resorption of the proximal femur is often thought to be related to reduction of stresses, when compared to those in the intact bone. Interface bone resorption and remodeling, which precedes the occurrence of fibrous tissue membranes, have been attributed to several causes. There is little dispute that in the initial stage, directly following implantation, a small layer of bone is necrotized and resorbed at the interface. This dead bone is a result of mechanical (vascular) damage during the bone preparation, ieakage of cell-toxic monomer (monomethylmethacrylate) out of the acrylic cement mixture, and/or thermal damage due to heat generated within the curing cement $(4,5)$.

In a subsequent process of bone resorption and formation at the interface, stresses and strains probably play an important role to determine the eventual fixation strength. Whereas bone 


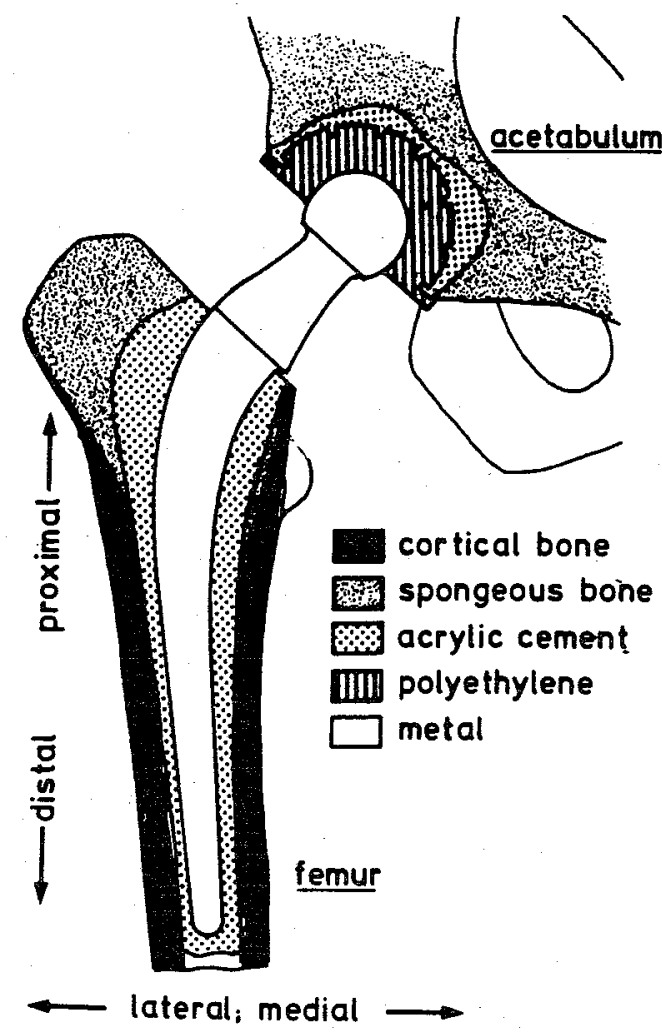

(a)

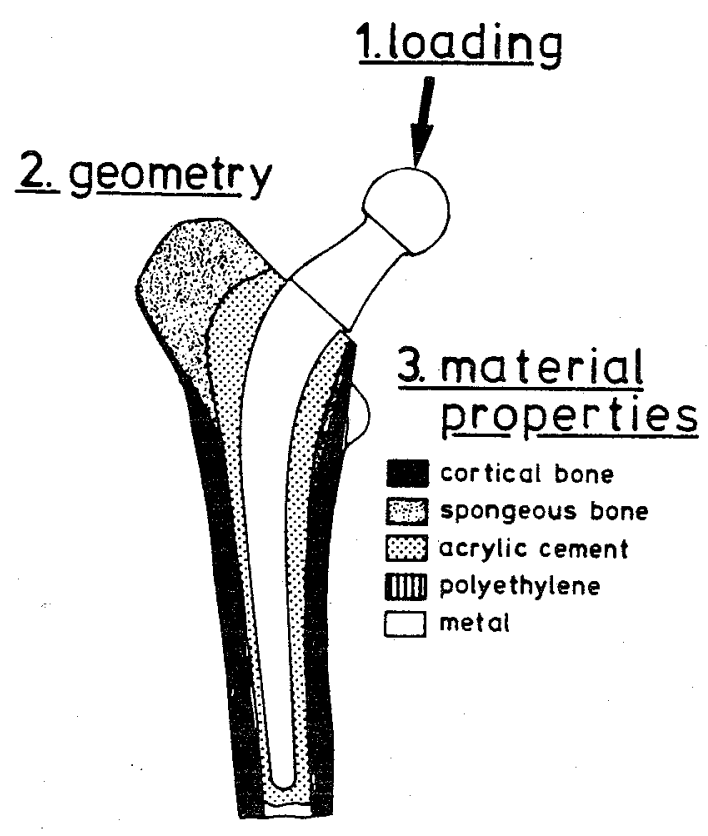

4. material connections

(b)

Fig. 1 (a) Schematic illustration of a (Charnley type) total hip replacement (THR); the metal and plastic components are fixated in the bone with a filling material, acrylic bone cement, a selfcuring polymethylmethacrylate (PMMA); (b) the stress distribution within the materials and at their connections depends on four structural aspects, as indicated in the figure.

resorption and the formation of a soft fibrous tissue membrane between the implant and the bone can probably not be avoided altogether $(2,4-7)$, subsequent bone formation in that layer no doubt depends on local stresses and micromotions, and thus on joint loading (8).

It is obvious from the previous discussion that local stresses and strains play an important role in the chances for long-term survival of bone-prosthesis structures, in view of both structural strength and biological interface reactions. These stresses and strains are generated in the process of load transmission from the prosthesis to the bone, which is the most important function of the fixation structure ( 9 ). 
The distribution of these stresses (Fig. 1.b), their magnitudes and orientations throughout the structure, depends on structural properties, i.e. loading characteristics, geometry, material properties and physical conditions at the interfaces. Hence, the stresses occurring within the materials of the structure and at their interfaces depend not only on the joint load, but also on the prosthetic. design specifications and the way in which the components are placed into the bone. Optimal stress distributions, in other words, can only be obtained with optimal designs and fixation techniques. To evaluate stresses and study their dependency on structural properties, stress analyses must be carried out. A relatively large number of such analyses have been reported in the recent orthopaedic biomechanics literature, many of which aimed at shedding light on the mechanical behavior of boneprosthesis structures, particularly in THR. Many interesting questions were addressed in these analyses, as for instance the effects on the stress distributions of acrylic cement layer thickness, implant material properties and design, joint loading, and fixation techniques. The aims and scopes of these stress analyses, and the three most commonly applied methods, i.e. experimental strain-gage techniques, analytical ("closed-form") solutions, and finite element methods, are briefly discussed in the following sections.

\section{EXPERIMENTAL STRAIN-GAGE ANALYSIS}

To understand the principles of experimental stress analysis, it must be appreciated that stresses cannot be determined directly, but only indirectly, by measuring their effects. The effects are deformations, represented by displacements between points, or strains. of all strain measuring methods feasible (e.g. 10), strain-gage techniques have been applied most frequently in biomechanics (11).

Electrical strain-gages are based on the principle that the resistance of a material changes when stretched. The gage consists of a small electrical resistance which is glued to the surface of the structure, in a certain orientation. The change in voltage over the resistance is directly proportional to the relative change in its length. Thus, the strain registered is an average value over the length of the gage along its specific orientation. Strain gages are generally suitable to measure strains at free surfaces, where the strain state can be characterized by three variables, two principal strain magnitudes and the principal strain direction. These variables can be obtained by using strain rosettes with three elements, each registering strain in its specific direction. The stresses can subsequently be calculated from the measured strains, using Hooke's law of linear elasticity and the material properties $(e . g .11,12)$. 


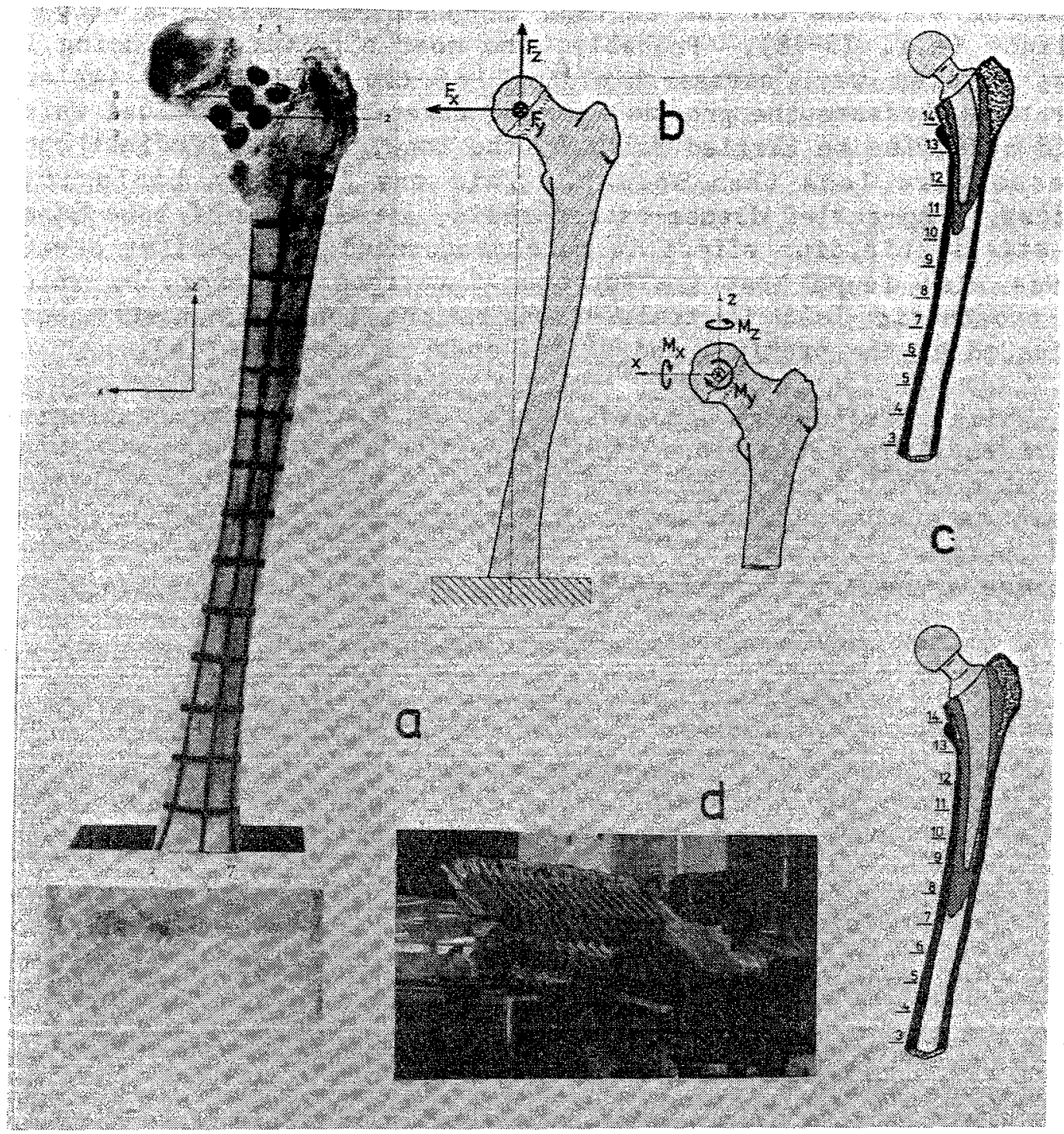

Fig. 2 Experimental strain gage analysis of a femur. Strain gages were attached at the intersections of the black lines (a); forces in 3 directions and moments in 3 planes were applied to the head (b); measurements were performed on the intact femur and after insertion of various hip prostheses (c); and (d) shows the laboratory setting (reproduced from Ref. 19).

Strain gages have frequently been used in stress analyses of bones, both in vivo (e.g. 13), and in vitro (e.g. 14). An example of a laboratory setting of a human femur is shown in Fig. 2. In this particular case, the strains on the femoral surface were evaluated not only to siudy the mechanical behavior of the intact bone under loading, but also to evaluate the influences of hip replacement by intramedullary prostheses (14). Other studies of this kind were also carried out by other investigators, all 
comparing stresses on the surface of the femur with and without implants (e.g. 15-18). Probably, the most significant finding in these studies was "stress-shielding" of the bone by the implant (Fig. 3). Because the prosthetic stem takes part of the load which would otherwise be carried fully by the bone, the longitudinal bone stresses are less than normal. This may induce a biological process of so-called disuse-osteoporosis, a reduction of bone mass. The stress-shielding effect is more pronounced with stiffer stems. It was also found that implant-bone interface stresses, by which the prosthetic load is transferred to the bone, is mostly concentrated at the proximal and distal ends of the stem (16).

While strain-gage analyses are we11-suited for exploring experimental investigations and for verification purposes of theoretical models, their limitation to free surfaces usually prohibits a more extensive evaluation of strains inside the structure. For this purpose theoretical prediction methods, as "closed-form" theories or numerical finite element methods, must be used.
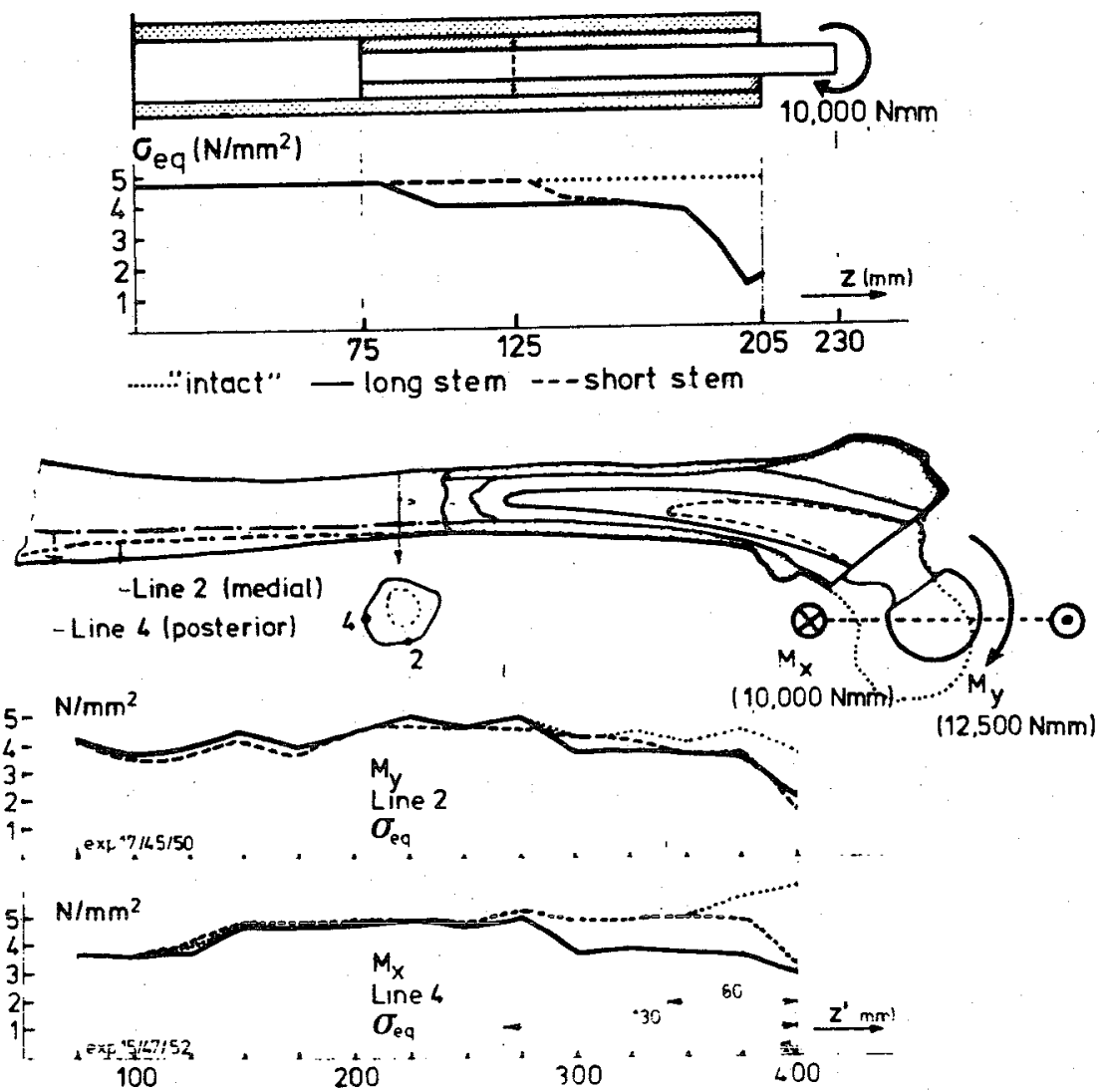

Fig. 3 Equivalent stresses at the outside surface of the femur, intact and with two bending couples in different planes, respectively. On the proximal side of the stem, the "stressshielding" effect of the stems with respect to the bone is easily. recognized, and again emphasized in a simplified, general model of the intramedullary fixation structure (reproduced from Ref. 19). 


\section{ANALYTICAL ("CLOSED-FORM") ANALYSIS}

In experimental stress analysis a physical model is used, which for example can be a prototype. In theoretical analysis the model is mathematical, $i . e$. a set of equations. Theoretical methods can be divided into analytical and numerical ones. The former is used if the four structural aspects, discussed earlier, can be made to fit into a mechanics theory, for which "closed-form" solutions exist. In this case, the mathematical equations are solved directly, yielding formulas in which the stress magnitudes are directly related to the parameters describing the structural aspects. Numerical methods, including finite element methods, are based on the use of computers. The complex mathematical problem is reduced to a numerical procedure and the relationship between the resultant stress values and structural parameters is usually not obvious. Examples of closed form theories which are frequently applied in biomechanics are linear-elastic bar theory, beam theory and torsion shaft theory. All three are valid for slender, prismatic bodies whose length is much larger than the thickness, made out of linear elastic, isotropic and homogeneous materials, loaded in axial tension or compression, transverse forces or bending, and torsion, respectively. These theories are available for 2-D and 3-D structures, uniform and variable cross-sections, straight and curved bodies. Although, particularly in biomechanics, structures seldom behave exactly in accordance with these theories, approximative models can sometimes be developed. Prosthetic stems, bone pins and rods are,good examples of structures that yield to these theories. Other examples include bone plates, although the holes present a complication, and diaphyses of long bones, by a rough approximation (14). Other simple closed-form theories used in hard tissue biomechanics are compound-beam theory (applied to bonefixation plate and bone-prosthetic stem composites), beam-onelastic-foundation theory (prosthetic stem and tibial plateau fixation), and plate and shell theories (skul1).

Closed-form solutions are attractive for obtaining approximative solutions for certain problems. They often give a direct insight into relations between essential structural parameters and stress behavior. Their application is cheap, leads to results rapidly and they are therefore often used to obtain first-order reference solutions for more advanced experimental and numerical analyses.

As an example of an analytical analysis, which is relevant for the hip joint prosthesis-bone structure, consider a generalized intramedullary cemented stem structure with a uniform axisymmetric cross-section (Fig. 4). We limit ourselves to axial loading $\left(\mathrm{N}_{\mathrm{O}}\right)$, other loading cases have been discussed elsewhere $(9,19)$. The question is how this load is transferred from the stem to the bone 
through the cement layer, and in what way is the load-transferring mechanism influenced by the structural parameters.

To fit this problem to a closed-form theory, it is assumed that the stem and the bone, separately, behave according to bar theory, i.e. that their cross-sections remain plane in deformed state $(e . g .20)$. This implies that the axial stresses, $\left(\sigma_{z}\right)$, in a cross-section are distributed homogeneously (Fig. 4). We then define the internal stem force, $\mathrm{N}_{\mathrm{s}}(z)$, and the internal bone force, $\mathrm{N}_{\mathrm{b}}(\mathrm{z})$, according to

$$
N_{s}=\sigma_{z s} A_{s} \quad \text { and } \quad N_{b}=\sigma_{z b} A_{b}
$$

where the subscripts $s$ and $b$ denote stem and bone respectively, and $A$ is the cross-sectional area. We further define the axial rigidities

$$
P_{s}=A_{s} E_{s} \quad \text { and } \quad P_{b}=A_{b} E_{b}
$$

where $\mathrm{E}$ is the Young's modulus of the material concerned.

A

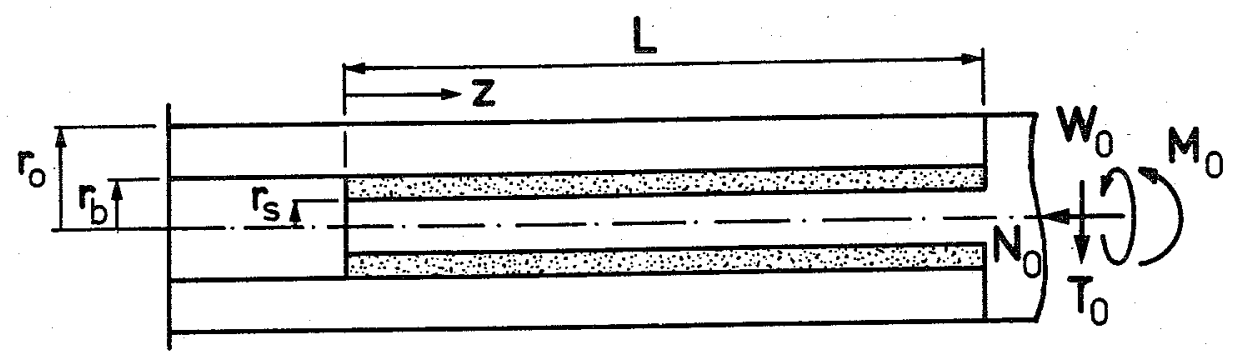

B
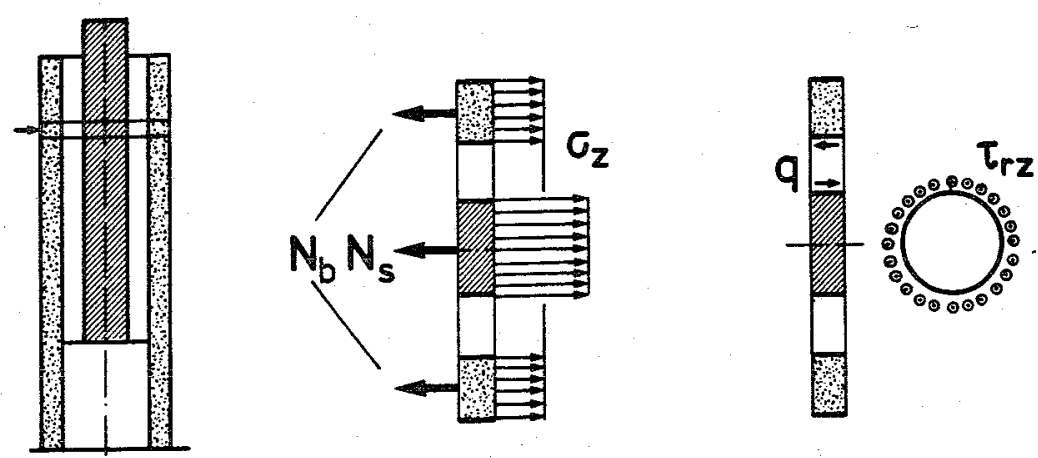

Fig. 4 (a) A general, axisymmetric model of an intramedullary fixation structure; (b) when loaded by an axial force, the primary bone and stem stresses are in the axial direction $\left(\sigma_{z}\right)$ and can be lumped into internal axial forces $\mathrm{N}_{b}(z)$ and $\mathrm{N}_{S}(z)$; the primary stresses in the cement layer and at the interfaces are axial shear stresses $\left(\tau_{r z}\right)$, which can be lumped into the internal axial shearing load $q(z)$. 
We assume that the axial stresses in the cement layer are negligible when compared to those in the bone and the stem. The axial shear stress, $\tau_{\mathrm{rz}}$, in the cement layer and at the interfaces depends on the radius $r$ (Fig. 4). However, from local equilibrium consideration it follows that $r_{\tau_{r z}}$ is constant in a cross-section. The internal, distributed shearing load $q(z)$ in the cement layer and at the interfaces is the local resultant of these shear stresses in a cross-section and is defined as

$$
q(z)=2 \pi r \tau_{r z}
$$

The stiffness of the cement layer against shear, $C_{n i}$, can be defined as

$$
q=c_{n}\left(w_{b}-w_{s}\right)
$$

where $w_{b}(z)$ and $w_{S}(z)$ are the axial deflections of the bone and the stem, respectively. $C_{n}$ can be approximated by

$$
c_{n} \simeq-\pi E_{c} /\left(1+\nu_{c}\right) 1_{n}\left(r_{s} / r_{b}\right)
$$

where $E_{c}$ and $\nu_{c}$ are Young's modulus and Poisson's ratio of the cement, respectively (19).

Applying the differential equations for bar theory gives

$$
P s \frac{d^{2} w_{s}}{d z^{2}}+q=0 \quad \text { and } \quad P b \frac{d^{2} w_{b}}{d z^{2}}-q=0
$$

which, together with Eqn. 4 and the appropriate boundary conditions gives solutions for $N_{S}(z), N_{b}(z)$ and $q(z)(19,20)$.

In these solutions, two important lumped parameters appear,

the relative stem rigidity: $\varepsilon_{n}=P_{s} /\left(P_{s}+P_{b}\right)$

the fixation exponent:

$$
\lambda_{n}=\sqrt{C_{n}\left(\frac{1}{P_{s}}+\frac{1}{P_{b}}\right)}
$$

An example of results for specific parameter values is shown In Fig. 5, for the case that stem collar-bone contact is present, and for the case that the collar is not mechanically effective. These results clearly illustrate the load-transferring mechanism: at the proximal side the load, $\mathrm{N}_{\mathrm{O}}$, is fully carried by the stem. In the proximal load-transferring region, a part of this load is transferred to the bone, through the cement, which generates high cement and interface loading, $q(z)$. 


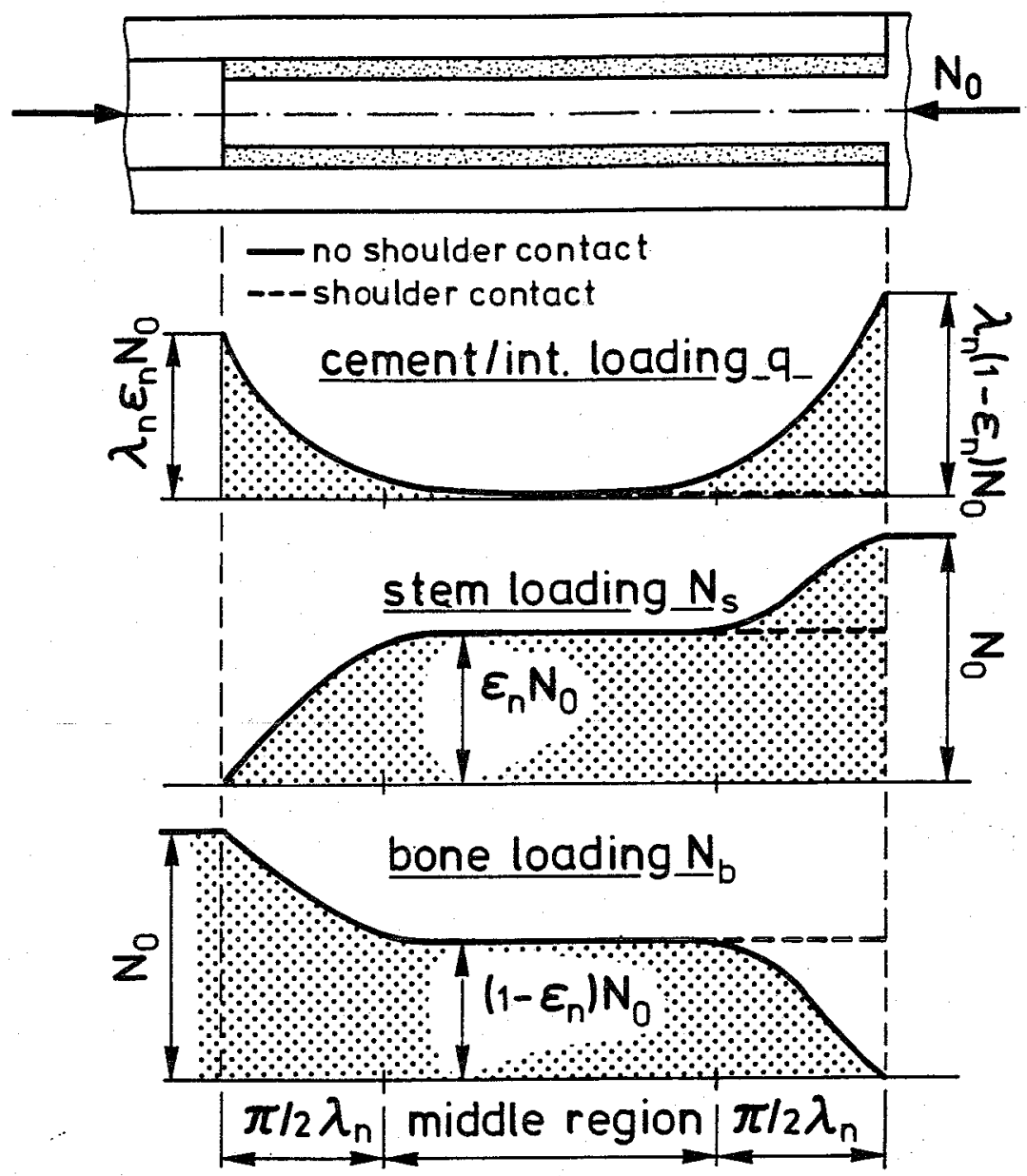

Fig. 5 Cement/Interface shearing load, $q(z)$, stem axial internal force, $N_{S}(z)$, and bone axial internal force, $N_{b}(z)$, as calculated with the closed-form theory (see text). If the stem is sufficiently long, the proximal and distal shear load concentrations in the cement, the loading ratio between the stem and the bone, and the lengths of the load transmission regions follow from simple formulas, shown in the graphs, and depend on the fixation exponent $\lambda_{n}$, the relative stem rigidity $\varepsilon_{n}$, and the external force $N_{O}$ $(9,19)$.

In the middle region the load is shared by the stem and the bone depending on their stiffness ratios, indicating a "stress-shielding effect; and at the distal side the final portion of the stem load is transferred to the bone, again through high cement and interface loading, $q(z)$. The load-transferring mechanism occurs in this way only if the stem is sufficiently long, i.e. if $\mathrm{L}>\pi / \lambda_{\mathrm{n}}(19)$. In this case, the most significant stress values can be directly 
approximated in the structural parameters, as indicated in Fig. 5 . For instance, using Eqn. 3 and the expressions in Fig. 5, the maximal cement stresses are,

$$
\begin{array}{ll}
\text { on the proximal side: } & \tau_{s p}=\lambda_{n}\left(1-\varepsilon_{n}\right) N_{o} / 2 \pi r_{s} \\
\text { on the distal side: } & \tau_{s d}=\lambda_{n} \varepsilon_{n} N_{0} / 2 \pi r_{s}
\end{array}
$$

In the process of developing this model, many simplifications were made. However, comparing the results of the formulas with those of more sophisticated finite element analysis of the same model, shown in Fig. 8, gives excellent agreement (19).

It is obvious that the model used in this case is a very simple one compared to the reality of hip prostheses fixated in bone. However, the results can be used in a qualitative way. For example, it can be seen from Eqns. 9 and 10 that reduction of $\lambda_{n}$ without changing $\varepsilon_{n}$ reduces the cement and interface stresses on both the proximal and distal sides. Referring to Eqn. 8, this implies reduction of $C_{n}$ by reducing, for example, the cement Young's modulus $E_{c}$. Another significant finding relates to the length of the stem: lengthening the stem beyond $L \simeq \pi / \lambda_{n}$ onily shifts the distal load-transfer region, and does not result in a stress reduction. Finally, it follows directly from Eqns. 9 and 10 that when $\varepsilon_{n}=0.5$, the distal and proximal cement/interface stresses are equal. Reducing the stem stiffness, by reducing its modulus or thickness, reduces $\varepsilon_{\mathrm{n}}$, hence increases the proximal stresses and reduces the distal ones. Increasing the stem stiffness has the opposite effect.

These and comparable qualitative effects can conveniently be assessed with simple analytical analyses of this kind $(9,19)$. In some cases a structure is such that predictions from these simple models can also have quantitative value, for example in intramedullary custom-fit prosthesis for tumor-resection patients (21). In most cases, however, more precise quantitative evaluations of internal stresses in bone-prosthesis structures will have to rely on numerical finite element methods.

\section{FINITE ELEMENT ANALYSIS}

The Finite Element Method (FEM) was introduced in the orthopaedic literature in 1972 (22), about 15 years after it initiated a revolution in stress analysis of structures in engineering mechanics (23). The early applications concerned stress analysis of entire bones. Then, for the first time, the irregular structural features of human bones, both in geometry and in material properties, could be realistically included in the stress analysis. 
The subsequent exponential growth of FEM applications in orthopaedic research, however, was not purely due to the interest in bone function, but mainly due to a need for realistic stress data on artificial joints and their mechanical interaction with the host bones.

The principles of the FEM are treated in depth by Zienkiewicz (23) and others, whereas a general description of its possibilities and limitations specifically in orthopaedic biomechanics were published elsewhere $(11,24)$. The following brief description, however, may help those who are not familiar with the FEM.

In using the method, a model of the structure to be analysed is defined first. This step entails the definition of external loads, geometry, material properties and material connections in a form which can be described in quantifiable terms, mathematically or numerically. This implies that certain assumptions and simplifications must be introduced. The nature of these simplifications determines whether the model, and hence the result, are realistic in a quantitative, or only in a qualitative sense. This model is then mathematically divided into a number of elements, connected at specific locations, called nodal points or nodes (Fig. 6). The connections and external loads are then defined numerically in boundary nodes. Every element is assigned one or more parameters, such as moduli of elasticity, which define its elastic behavior. The computer program calculates the stiffness characteristics of

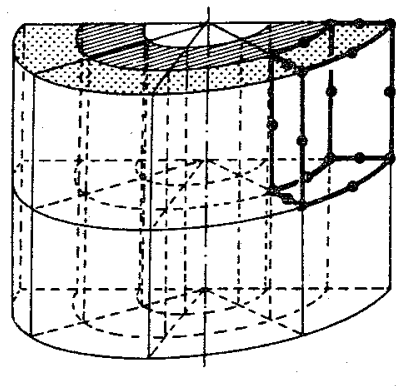

a
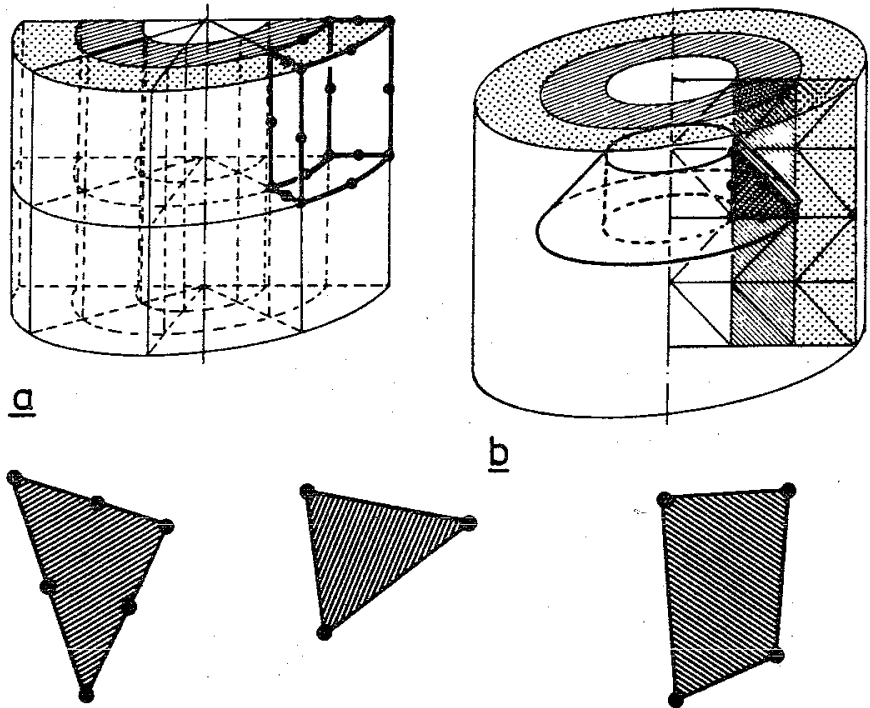

c

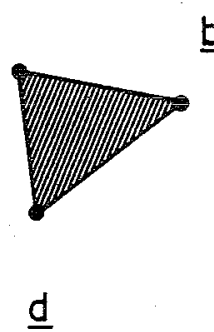

$\underline{b}$

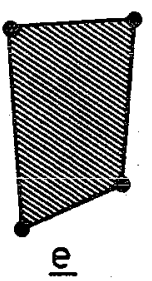

Fig. 6 A number of different element types, (a) 20-node isoparametric hexahedron for 3-D models, (b) 6-node axisymmetric ring element, (c) 6-node and (d) 3-node triangles, and (e) 4-node quadrilateral element for 2-D analysis (reproduced from Ref. 24)。 
each element and assembles the element mesh through mutual forces and displacements in each node. In fact, the FEM program solves a large number of equations that govern force equilibrium at element nodes. The computer time needed, and thus the cost of analysis, increase with the number of elements and nodes.

The solution obtained with this method is approximate in the sense that it converges to the exact solution for the model when the mesh density approximates infinity. Thus, the accuracy of a FEM model can be checked by refining the mesh and comparing the results obtained with the refined mesh to the original one. This is called the convergency test. In interpreting the FEM results we must differentiate between the validity of the model, i.e. the precision by which the entity of mathematical descriptions of structural properties mimic the real structure, and the accuracy of the model, which is the precision by which the FEM mesh can approximate the exact solution for that model. Only the accuracy can be checked with a convergency test, the validity must be assessed by experimental verification or other means.

A variety of element types are usually available for threedimensional (3-D) and two-dimensional (2-D) structures in a FEM computer package (Fig. 6). The computer time required for 3-D element is many times more than that for 2-D elements. Because of its cost efficiency, mesh accuracy is easier to obtain in a 2-D model; however, 3-D models are often more realistic.

FEM programs are usually applied in combination with pre-processors and post-processors, which are computer programs that handle the element division, i.e. mesh creation, and graphical representation of the results, respectively.

The use of the FEM has been reported during the last decade in an increasing number of orthopaedic biomechanics publications, and include studies of stress related bone architecture and bone remodeling processes, design and optimization of artificial joints and fracture fixation devices, and mechanical analyses of tissues such as articular cartilage and intervertebral discs (24). The greater part of the FEM analyses was focused on joint replacement, in particular the total hip prosthesis. Early models of this structure were all 2-D ones (e.g. 25-27). A problem in 2-D models of the intramedullary hip joint fixation is to account for the 3-D structural integrity of the bone, which surrounds the implant. A solution can be found in attaching side plates to the 2-D model, thus using two superimposed element layers, an example of which is shown in Fig. 7. Another solution for simplified modeling is assuming the geometry to be axisymmetric, as illustrated in Fig. 8 (e.g. 19, 21). A more general description of the intramedullary fixation structure can be obtained in this way, which is suitable 


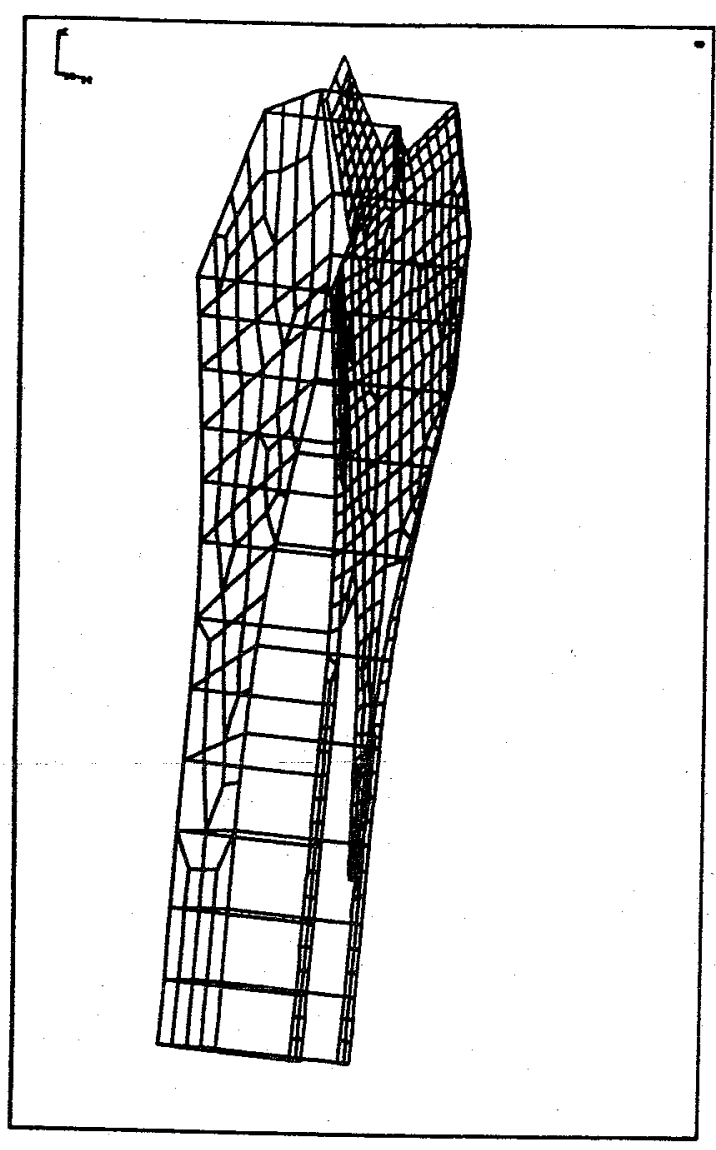

Fig. 7 A 2-D FEM model of a femoral THR structure, using a sideplate to account for the 3-D integrity of the bone.

for extensive parametric analysis and used to establish the principal concepts of the load transmission mechanism.

"Anatomic" 3-D FEM models (e.g. 28-31), of course, are more precise in their geometrical descriptions, but more tedious to handle. Also, numerical accuracy is often difficult to obtain due to computer time requirements and memory space limitations. In addition, these models are very costly, hence are more suited to compare specific designs in a relative sense, than for parametric analysis and design optimization.

A11 these FEM analyses concerned prostheses fixated with acrylic cement. Several questions regarding design and fixation of these implants were addressed, and the results published certainly led to a better understanding of their mechanical behavior, and the development of more rational designs. However, many important questions remain unanswered, mainly because the short- and longterm effects of stresses and strains on biological bone behavior at 
the implant interfaces are essentially unknown. In most models, linear elasticity, isotropy and homogeneity of bone were assumed.

A specific problem in analyses of bone-prosthesis structures is the description of the implant-bone connection. Although these materials are usually not rigidly connected in reality, this is assumed to be the case in almost all models. It was shown that this assumption leads to results which are not totally realistic, particularly for the stress distribution near these connections $(19,27,32)$.

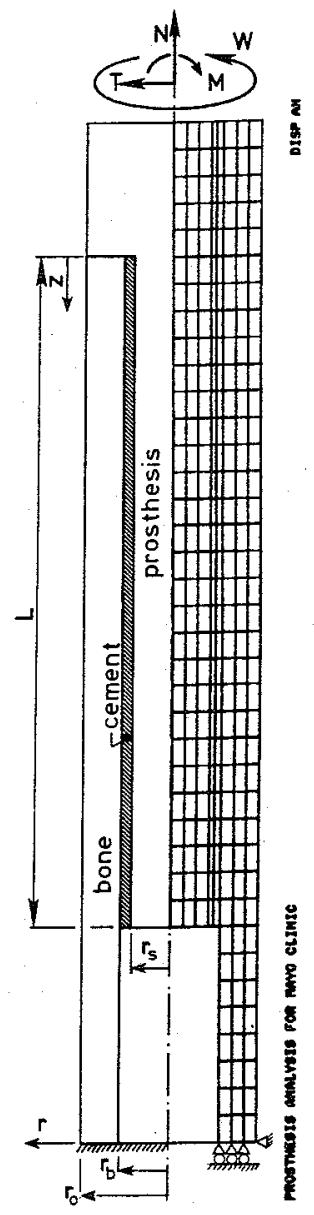

A
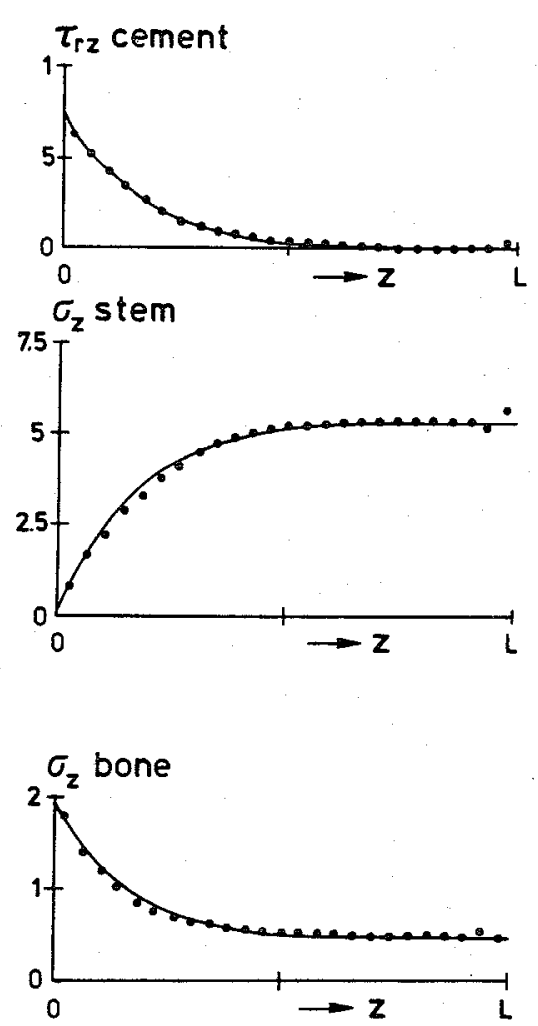

axial force

Fig. 8 (a) Axisymmetric FEM model of a "custom-fit" prosthesis fixation system (reproduced from Ref. 21); (b) some results obtained with this model for axial loading (assuming ideal collarbone contact), stem-cement interface shear stresses ( $\left.\tau_{r z}\right)$, stem and bone axial direct stresses $\left(\sigma_{z}\right)$, compared with analytical (closedform) solutions (see Section 3, and Fig. 5). With the FEM model, contrary to the analytical model, other stress components can be evaluated as well $(19,21)$. 
FEM analyses of the acetabular component of total hip replacement have become popular only recently (e.g. 33, 34), probably due to the fact that complications of this part have become manifest in patient populations relatively late post-operatively. In addition, the pelvis and the acetabulum are difficult to model, due to their geometrical and material complexities.

Another hip replacement procedure that attracted interest from FEM analysts is the relatively new resurfacing prosthesis, which was studied with $2-D(35)$ and axisymmetric 3-D (36) models.

Other joints that received some attention include the knee and the finger joints. Artificial knee hinges were investigated using axisymmetric 3-D (37) and full 3-D (38) FEM models. The tibial plateau fixation of unconstrained knee prostheses were studied with 2-D models (39), axisymmetric models (40), and 3-D models $(41,42)$. A new finger joint prosthesis was evaluated with axisymmetric FEM models (43).

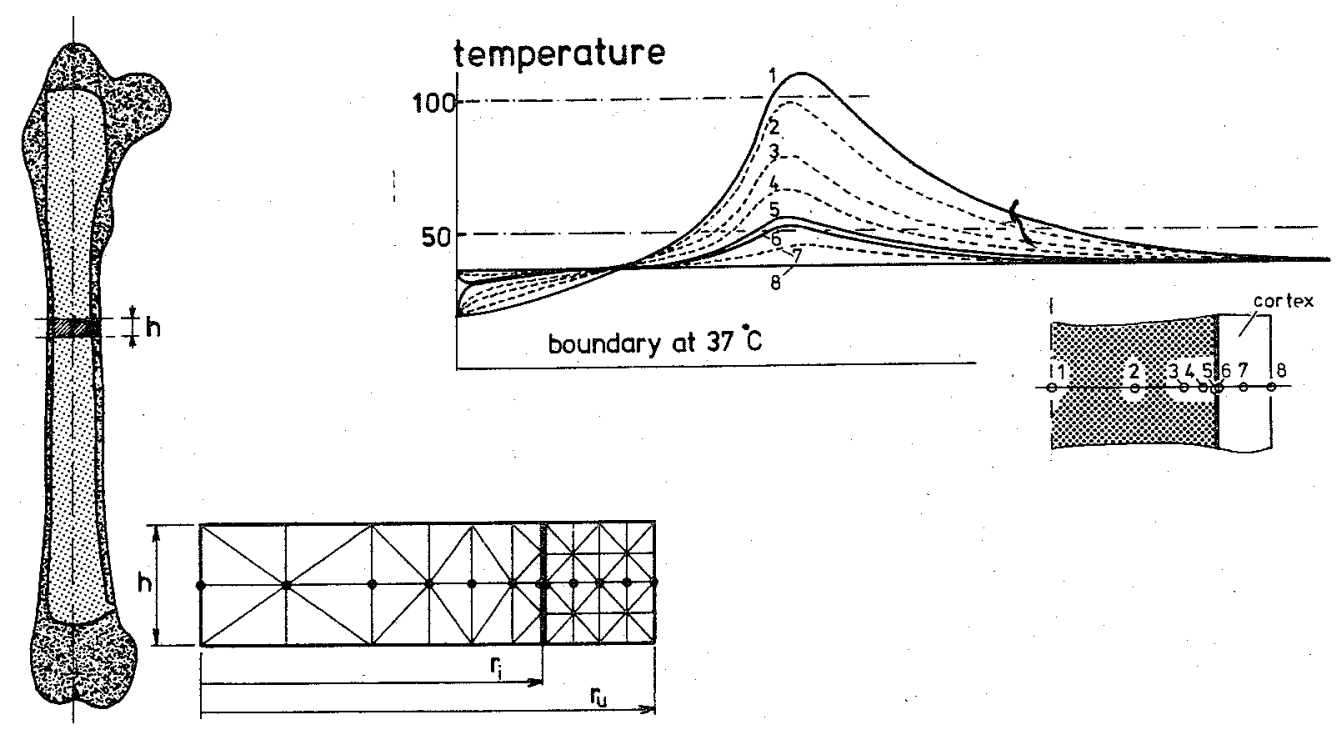

Fig. 9 FEM analysis of the transient heat generation and conduction process in and around acrylic bone cement in the curing phase. This particular model (left) is used to simulate an animal experiment in which cement is injected into rabbit femurs, and bone necrosis is studied histologically. The transient temperatures at several locations in the cement mass and in the bone cortex, calculated in the FEM analysis, are shown on the right; the peak temperature is reached in about 350 seconds (reproduced from Ref. 5). 
Finally, a different type of biomechanics implant problem was also addressed with the FEM, using this method as a universal numerical tool to solve problems of heat and mass transfer in geometrically complex regions. An example of such a problem is the nonsteady heat generation and conduction that occurs in and around acrylic cement during its curing phase whle fixing an implant. The bone close to the cement rises in temperature and may undergo thermal necrosis. To investigate this process and evaluate the transient temperature distributions, the FEM was applied to simulate implant fixation in the femur and in the acetabulum (5, 44). An example of such a study is illustrated in Fig. 9.

\section{DISCUSSION}

Although the FEM has enhanced developments in orthopaedic biomechanics in general and artificial joint design in particular, its application in this area is still in an early stage. Several problems still hamper the use of stress analysis, the FEM in particular, to its full potential. Two aspects of bone-prosthesis structures specifically need attention in biomechanics research.

The first aspect is related to the complexity of the structures to be modeled and their individual variability, on the one hand, and limitations in computer capacities on the other. Even if the individual structural parameters, in terms of geometry and material properties, and loading histories of individual patient cases could be assessed with adequate precision, the costs of FEM would still prohibit individual case analysis, other than in exceptional circumstances. Hence, the objectives of investigations of this kind must be to provide general information on a relative basis. Even with this aim, the vagaries of the bone-prosthesis structure in general present numerous problems that have yet to be solved.

If we put the kind of information that can be obtained from stress analyses on a scale, ranging from general (qualitative, global) to specific (quantitative, local), it is evident that such a scale can be related to a scale of model sophistication, ranging from coarse to refined. Taking the THR structure as an example, we would find the strain-gage analysis and analytical ("closed-form") methods discussed previously on the coarse side, and 3-D, "anatomic" FEM models on the refined. Nevertheless, the information on the full scale must be compatible. Unfortunately, this is not always the case in the present state of the art, and further analyses of an experimental and theoretical nature, combined with clinical evaluations must be performed in order to fill the gaps in our knowledge. 
Secondly, it is on the refined side of the scale in particular that we meet limitations of modeling feasibilities. These are not only related to limitations in computer capacities, which are progressively approached when $3-D$ mesh density is increased, but also to requirements of more precise descriptions of material properties and material connections, which are simply not available as yet. Hence, highly sophisticated experimental work is needed for the required data to supply the increasingly refined models, before progress in that direction can be made.

The second aspect concerns the reactions of bone to implants, and their presumed relations to stresses and strains. Any model, whether experimental, analytical or numerical, represents a particular bone-prosthesis structure at a particular point in time, e.g. immediately post-operative. Stresses and strains, determined for such a configuration have a significance for design purposes when they can be compared to stress-criteria, as the strength of bone, acrylic cement, and the implant materials. However, no such criteria exist for stresses or strains that would cause interface bone resorption or bone osteoporosis. In addition, these biological reactions would result in geometrical and/or material changes which, in turn affect the stresses and strains again. This biological feed-back loop in the structural behavior is illustrated in Fig. 10.a. It would be possible in principle to describe this 10op mathematically (45), and incorporate it into FEM analysis to predict the eventual stress distribution. This, of course, would require experimental data on stress (strain) - bone remodeling relations which are not yet available.

The stresses in Fig. 10.a are called "global stresses". It is evident that the stresses predicted in a global FEM model of an entire bone-prosthesis configuration can only be considered as rough lumped internal loading variables for a small piece of bone material. However, it is probably based on the local stress state that bone reacts biologically. Hence, it is likely that stresses must be determined in detailed models which take local geometry and properties into account before a feed-back loop can be incorporated (Fig. 10.b). Although it is not realistic to assume that a FEM model can be realistic both on a global and a local level, a multiple model approach can be adopted to overcome this problem.

Despite the potential feasibilities of numerical methods, these techniques cannot be applied for objective stress and remodeling predictions until consistent quantitative experimental data on relations between stresses (strains) and bone remodeling are available. Nevertheless, analyses of this kind could certainly enhance developments in experimental work, in particular if the two approaches were combined in efforts of a truly multidisciplinary nature. 
Stress Analysis and Fixation Problems in Joint Replacement

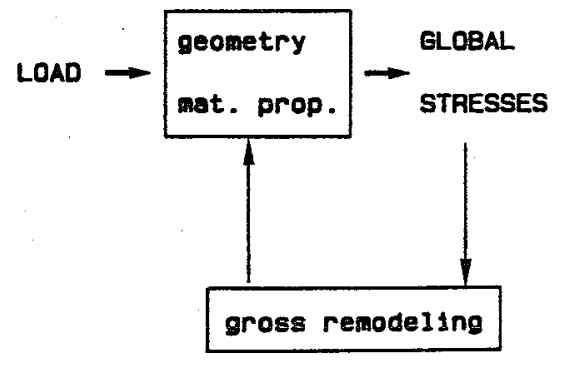

A

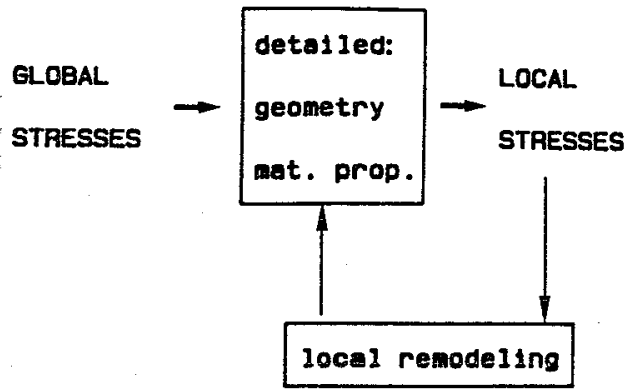

B

Fig. 10 Schemes for advanced stress analyses of bone-prosthesis structures, taking into account the biological feed-back loop. Because bone cells probably react to the local stress (strain) environment and FEM models cannot be realistic and detailed on all levels, a multiple model approach can be adopted ( $a$ and $b$ ).

\section{REFERENCES}

1. Consensus Development Panel, NIH-Consensus Paper: Total Hip Joint Replacement, Bethesda, MD. Partly published in JAMA, vol. 248 , no. 15 , (1982) p. 1817.

2. Charnley, J. The Long-Term Results of Low Friction Arthroplasty of the Hip Performed as a Primary Intervention. J. Bone Jt. Surg. 45-B (1972) p. 61.

3. Stauffer, R.N. Ten-Year Follow-up Study of Total Hip Replacement. J. Bone Jt. Surg. 64-A (1982) p. 1983.

4. Feith, R. Side-Effects of Acrylic Cement, Implanted into Bone. Acta Orthop. Scand. Supp1. no. 161, 1975.

5. Huiskes, R. Some Fundamental Aspects of Human Joint Replacement, Section II: Heat Generation and Conduction Analyses of Acrylic Bone Cement in Situ. Acta Orthop. Scand. Suppl. no. 185 (Munskgaard, Copenhagen, 1979) p. 43.

6. Willert, H.G. and M. Semlitsch. Problems Associated with the Cement Anchorage of Artificial Joints. In: Advances in Artificial Hip and Knee Joint Technology (Edited by N. Schaldach and D. Hohmann, Springer Verlag, Berlin, Heidelberg, New York, 1976).

7. Freeman, M.A.R., G.W. Bradley, and P.A. Revell. Observations upon the Interface between Bone and Polymethylmethacrylate Cement. J. Bone Jt. Surg. 64-B (1982) p. 489.

8. Radin, E.L., C.T. Rubin, E.L. Trasher, L.E. Lanyon, A.M. Crugnola, A.S. Schiller, I.L. Paul, and R.M. Rose. Changes in the Bone-Cement Interface after Total Hip Replacement. J. Bone Jt. Surg. 64-A (1982) p. 1188.

9. Huiskes, R. Design, Fixation and Stress Analysis of Permanent Orthopedic Implants: The Hip Joint. In: Functional Behavior 
of Orthopedic Materials (Edited by P. Ducheyne and G. Hastings, CRC-Press, Boca Raton, FL, vol. 2, ch. 5, 1983).

10. Durelli, A.J. The Difficult Choice: Evaluatioh of Methods Used to Determine Experimentally Displacements, Strains and Stresses. App. Mech. Rev. 30, 9 (1977) p. 1167.

11. Huiskes, R. Principles and Methods of Solid Biomechanics. In: Functional Behavior of Orthopedic Materials (Edited by $P$. Ducheyne and G. Hastings, CRC-Press, Boca Raton, FL, vol. 1, ch. 4, 1983).

12. Reilly, D.T. and A.H. Burstein. The Elastic and Ultimate Properties of Compact Bone Tissue. J. Biomechanics 8 (1975) p. 393.

13. Lanyon, L.E. The Measurement and Biological Significance of Bone strain in Vivo. In: Mechanical Properties of Bone. (Edited by S.C. Cowin, AMD - vol. 45, ASME, New York, 1981) p. 93 .

14. Huiskes, R., J.D. Janssen, and T.J. Slooff. A Detailed Comparison of Experimental and Theoretical Stress Analyses of a Human Femur. In: Mechanical Properties of Bone (Edited by S.C. Cowin, AMD - vol. 45, ASME, New York, 1981) p. 211.

15. Oh, I. and W.H. Harris. Proximal Strain Distribution in the Loaded Femur. J. Bone Jt. Surg. 60-A (1978) p. 75.

16. Jacob, H.A.C. and A.H. Huggler. An Investigation into Biomechanical Causes of Prosthesis Stem Loosening within the Proximal End of the Human Femur. J. Biomechanics 13 (1980) p. 159.

17. Crowninshield, R.D., D.R. Pedersen, and R.A. Brand. A Measurement of Proximal Femur Strain with Total Hip Arthroplasty. J. Biomech. Engrg. 102 (1980) p. 230.

18. Rohlman, A., G. Bergmann, and R. Koelbel. The Relevance of Stress Computation in the Femur with and without Endoprostheses. In: Finite Elements in Biomechanics (Edited by R.H. Gallagher et al., John Wiley and Sons, New York, 1982) p. 361.

19. Huiskes, R. Some Fundamental Aspects of Human Joint Replacement. Part III: Stress Analyses of Intramedullary Fixation Systems. Acta Orthop. Scand. Suppl. no. 185 (Munskgaard, Copenhagen, 1979) p. 109.

20. Timoshenko, S.P., and J.N. Goodier. Theory of Elasticity (3rd ed.) (McGraw-Hi11, Kogahuska, Tokyo, 1970).

21. Huiskes, R. and E.Y.S. Chao. Optimal Steem Design in Tumor Prostheses. In: Tumor Prosthesis for Bone and Joint Reconstruction (Edited by E.Y. Chao and J.C. Ivins, Thieme Stratton, New York, sect. 4, ch. 44, 1983) p. 367.

22. Brekelmans, W.A.M., H.W. Poort, and T.J.J.H. Slooff. A New Method to Analyse the Mechanical Behavior of Skeletal parts. Acta Orthop. Scand. 43 (1972) p. 301.

23. Zienkiewicz, O.C. The Finite Element Method (3rd ed.) (McGraw-Hi11, London, 1977).

24. Huiskes, R. and E.Y.S. Chao. A Survey of Finite Element Analysis in Orthopaedic Biomechanics: The First Decade. J. Biomechanics 16 (1983) p. 385 . 
25. McNeice, G.M.,. P. Eng and H.C. Amstutz. Finite Element Studies in Hip Reconstruction. In: Biomechanics V-A. (Edited by P.V. Komi, Univ. Park Press, Baltimore, MD, 1976) p. 394.

26. Andriacchi, T.P., J.0. Galante, T.B. Belytschko, and S. Hampton. A Stress Analysis of the Femoral Stem in Total Hip Prostheses. J. Bone Jt. Surg. 58-A (1976) p. 616.

27. Svensson, N.L., S. Valliappan, and R.D. Wood. Stress Analysis of Human Femur with Implanted Charnley Prostheses. J. Biomechanics 10 ( 19 ) p. 581 .

28. Roehrle, H., R. Scholten, W. Sollbach, G. Ritter, and A. Gruenert. Der Kraftfluss bei Huftendoprothesen. Arch. Orthop. Unfal1-Chir. 89 (1977) p. 49.

29. Hampton, S.J., T.P. Andriacchi, and J.0. Galante. Threedimensional Stress Analysis of the Femoral Stem of a Total Hip Prosthesis. J. Biomechanics 13 (1980) p. 443.

30. Crowninshield, R.D., R.A. Brand, R.C. Johnston, and J.C. Milroy. An Analysis of Femoral Component Stem Design in Total Hip Arthroplasty. J. Bone Jt. Surg. 62-A (1980) p. 68.

31. Tarr, R.R., I.C. Clarke, T.A. Gruen, and A. Sarmiento. Predictions of Cement-Bone Failure Criteria: Three-dimensional Finite Element Models versus Clinical Reality of Total Hip Replacement. In: Finite Elements in Biomechanics. (Edited by R. H. Gallagher et al., John Wiley and Sons, New York, 1982) P. 345 .

32. Rohlmann, A., G. Bermann, and R. Koelbel. Aussagewert und Grenzen der Spannungsberechnung mit der Finiten-Element-Methode (FEM) bei Orhtopadischen Problemen. Z. Orthop. 118 (1980) p. 122 .

33. Vasu, R., D.R. Carter, and W.H. Harris. Stress Distributions in the Acetabular Region-I. Before and After Total Joint Replacement. J. Biomechanics 15 (1982) p. 155.

34. Pedersen, D.R., R.D. Crowninshield, R.A. Brand, and R.C. Johnston. An Axisymmetric Model of Acetabular Components in Total Hip Arthroplasty. J. Biomechanics 15 (1982) p. 305.

35. Shybut, G.T., M.J. Askew, R.Y. Hori, and S.D. Stulberg. Theoretical and Experimental Studies of Femoral Stresses Following Surface Replacement Hip Arthroplasty. In: The Hip, chap. 10 (The C. V. Mosby Co., St. Louls, MO, 1980) p. 192.

36. Huiskes, R. and J. van Heck. Stresses in the Femoral Head-Neck Region after Surface Replacement, a Three-dimensional Finite Element Analysis. Proceedings 27 th Annual Meeting Orthop. Res. Soc. (1981) p. 174 .

37. Croon, H.W., D.H. van Campen, J. Klok, and R. Miehlke. Quasi Two-dimensional FEM Analysis and Experimental Investigations of the Tibial Part of Knee Endoprostheses with Intramedullary Stems. In: Biomechanics: Principles and Applications. (Edited by R. Huiskes et al., Martinus Nijhoff Publ., The Hague, Boston, London, 1982) p. 313.

38. Roehrle, H. W. Sollbach, and J. Gekeler. Stress Analysis in Artificial Knee Joints with Fixed and Movable Axis Using the 
Finite Element Method. In: Biomechanics: Principles and Applications (Edited by R. Huiskes et al., Martinus Nijhoff Publ., The Hague, Boston, London, 1982) p. 305.

39. Askew, M.J. and J.L. Lewis. Analysis of Model Variables and Fixation Post Length Effects on Stresses around a Prosthesis in the Proximal Tibia. J. Biomech. Engng. 103 (1981) p. 239.

40. K. Murase, R.D. Crowninshield, D.R. Pedersen, and T.S. Chang. An Analysis of Tibial Component Design in Total Knee Arthroplasty. J. Biomechanics 16 (1982) p. 13.

41. Barte1, D.L., A.H. Burstein, E.A. Santavicca, and J.N. Insall. Performance of the Tibial Component in Total Knee Replacement. J. Bone Jt. Surg. 64-A (1982) p. 1026.

42. Lewis, J.L., M.J. Askew, and D.P. Jaycox. A Comparative Evaluation of Tibial Component Designs of Total Knee Prosthesis. J. Bone Jt. Surg. 64-A (1982) p. 129.

43. Huiskes, R., J. van Heck, P.S. Walker, D.J. Green, and D. Nunamaker. A Three-dimensional Stress Analysis of a New Finger-Joint Prosthesis Fixation System. In: Int. Conf. Proceedings on Finite Elements in Biomechanics (Edited by B.R. Simon, Univ, of Arizona Press, Tucson, AZ, 1980) p. 749.

44. Swenson, L.W., D.J. Schurman, and R.L. Piziali. Finite Element Temperature Analysis of a Total Hip Replacement and Measurement of PMMA Curing Temperatures. J. Biomed. Mat. Res. 15 (1981) p. 83.

45. Cowin, S.C. Continuum Models of Adaption of Bone to Stress. In: Mechanical Properties of Bone (Edited by S.C. Cowin, AMD-vol. 45, the Am. Soc. of Mech. Engrs., New York, 1981) p. 193. 